\title{
Concepção do Estado e Escolha da Metodologia de Avaliação de Políticas Públicas
}

\section{Notion of the State and Choice of Methodology for Evaluation of Public Policies}

\author{
Erni José Seibel ${ }^{1}$, Carmen Rosario Ortiz G. Gelinski²
}

\begin{abstract}
Resumo
Este artigo tem por objetivo discutir as principais visões sobre o processo de avaliação de políticas públicas, a partir da percepção que cada uma delas tem sobre as funções do Estado. Para isso, são expostas as percepções sobre o papel do Estado, ligadas ao pensamento neoclássico e ao Welfare State. A partir delas são levantadas as metodologias de avaliação de políticas públicas (gerencialista e não-gerencialista). As reflexões apontam para a necessidade de repensar o papel do Estado diante do grave quadro de necessidades sociais contemporâneas.
\end{abstract}

Palavras-chaves: Concepções de Estado. Políticas públicas. Metodologias de avaliação

\begin{abstract}
The objective of this paper is to discuss the main views to the assessment process of public policies, from the perception they have on the functions of the State. In order to achieve this goal, we review the perceptions on the role of the State according to the neoclassical thought and the Welfare State approach. After that, we develop evaluation methodologies for public policies (generalist and non-generalist ones). The conclusion points to the need for rethinking the role of the State before the serious situation related to the contemporary social demands.
\end{abstract}

Key words: Conceptions of state. Public policies. Assessment methodologies.

\footnotetext{
${ }^{1}$ Professor do Departamento de Sociologia Política de Universidade Federal de Santa Catarina. E-mail para contato: seibel@cfh.ufsc.br.

2 Professora do Departamento de Economia e Relações Internacionais da Universidade Federal de Santa Catarina. E-mail para contato: carmeng@cse.ufsc.br.
}

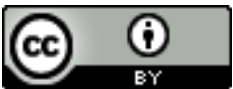

Esta obra foi licenciada com uma Licença Creative Commons - Atribuição 3.0 Não Adaptada. 


\section{Introdução}

As funções do Estado e seu papel é um debate já clássico e permanente em diversas áreas de conhecimento, entre elas a Economia, a Sociologia ou a Ciência Política. As grandes transformações engendraram no mesmo a incorporação e/ou desresponsabilização de funções públicas que expressam as tendências de sua estrutura econômica, política e social. O Estado contemporâneo incorporou práticas de gestão, quase sempre (re)traduzidas do universo gerencialista do capital. A primeira dessas práticas foi a função orçamentária. No Pós-guerra foi introduzido o planejamento e, a partir dos anos 80 , já por influência de instituições internacionais de fomento, o Estado incorpora a prática da avaliação das políticas públicas. Esses processos não ocorreram sem contradições, pois a sua incorporação implicou na internalização, pelo aparato estatal, de racionalidades de mercado, bem como de ordem política em conflito com racionalidades de caráter social. No caso brasileiro, esse embate é aflorado com o processo de democratização, na medida em que os segmentos sociais organizados pressionaram não somente por novas políticas públicas, mas também pela contestação à racionalidade gerencialista e clientelista das mesmas. Essa postura se apresenta novamente diante da função de avaliação de políticas publicas.

É objetivo deste artigo discutir as principais visões correntes de avaliação de políticas públicas $^{3}$, considerando a percepção que cada uma delas tem sobre as funções do Estado.

Quando se pensa em avaliação cabe ter em mente que as políticas econômicas têm seus mecanismos próprios - e consolidados - de avaliação. Por sua vez, a avaliação das políticas sociais é um campo que, no escopo das ciências administrativas, tem um relativo consenso, quanto aos conceitos e ferramentas

\footnotetext{
${ }^{3}$ Deve ser destacado, já de início, que o termo "políticas públicas" se refere a todo um leque de políticas implementadas pelo Estado, que podem ser englobadas em políticas econômicas (cambiais, fiscais, monetárias) e políticas sociais (saúde, educação, transporte, assistência social etc.). Entretanto, a referência às políticas públicas tem sido usualmente empregada para designar as políticas sociais, uso que será dado ao termo neste trabalho.
} 
necessárias para avaliar uma política pública. No entanto, dentro das Ciências Sociais, incluída aí a Economia, ainda é um assunto em construção. Tema de interesse crescente na Sociologia e na Ciência Política, os economistas tem se voltado, também, à análise das políticas públicas. $O$ assunto vem ganhando espaço em cursos de pósgraduação, em congressos e em publicações científicas. Mesmo assim, a questão específica dos elementos ou das variáveis a serem utilizadas para a avaliação está longe de constituir um conjunto de consensos.

A tentativa de sistematizar o debate da avaliação de políticas públicas esbarra no estabelecimento de critérios de ordem prática. O primeiro refere-se à própria concepção do Estado e às responsabilidades que o mesmo deve assumir. O segundo refere-se à própria concepção da avaliação, se gerencialista (mais "micro" ou focada nos custos) ou não-gerencialista (com ênfase nos processos políticos e nos atores).

Portanto, prévia à discussão sobre a avaliação das políticas públicas, devem ser estabelecidos os limites da ação do Estado que estão por trás das principais correntes da avaliação de políticas públicas. Para isso, e sem querer exaurir o debate, serão expostas, nas duas primeiras seções deste paper, as percepções sobre o papel do Estado, ligadas ao pensamento neoclássico e ao Welfare State. A seguir serão levantadas as metodologias de avaliação de políticas públicas (gerencialista e nãogerencialista) e, por último, são tecidas algumas considerações sobre a necessidade de se repensar o papel do Estado diante do pungente quadro de necessidades sociais.

\section{Eficiência fiscal e políticas públicas}

Na melhor tradição neoclássica, herdeira da concepção clássica do Estado de Adam Smith, Giambiagi e Além (1999, p.24) destacam que "a existência do governo é necessária para guiar, corrigir e complementar o sistema de mercado que, sozinho, não é capaz de desempenhar todas as funções econômicas". Nessa concepção, o Estado é necessário por, pelo menos, quatro motivos. O primeiro diz respeito à estrutura legal criada pelo governo, indispensável para proteger os contratos. O segundo refere-se à necessidade de produzir certos bens ou serviços que não poderiam ser produzidos por um sistema de mercado. Em terceiro lugar, a existência do Estado justifica-se porque, 
mesmo com um mercado operando sem travas, em condições de livre concorrência, nada garante que as expectativas da sociedade - em termos de emprego, geração de renda ou crescimento do PIB - sejam alcançadas. Por último, a intervenção do Estado justifica-se pelas externalidades, isto é, pelas ações decorrentes da atuação de outros agentes econômicos. As externalidades podem ser positivas, como a ação benéfica, para os moradores de um bairro, que resulta da limpeza de um terreno com focos de dengue. Podem, também, ser negativas, como no caso de uma indústria que despeja resíduos químicos num rio. Caberia ao Estado estimular (via subsídios) a ocorrência dessas externalidades, quando positivas, ou punir (via multas, impostos ou regulamentação) quando negativas.

Ao governo, na sua função alocativa ${ }^{4}$, caberia oferecer bens/serviços públicos. Isto é, aqueles bens que não são passíveis de ressarcimento por parte de quem os consome (como segurança pública), ou aqueles cujo consumo, por parte de alguns consumidores, não afeta a disponibilidade para outros consumidores (como a iluminação pública). A oferta de certos bens ou serviços por parte do Estado se justifica, para esta concepção, somente nos casos em que o mercado não tenha interesse econômico na sua produção. Mesmo assim, se depois de uma atividade ter sido prospectada pelo Estado e se tornar atrativa para a iniciativa privada deverá ser repassada a estes.

Em tese, a oferta de serviços públicos, como saúde, educação e segurança, estaria garantida pelo Estado não fosse a grande preocupação com o nível dos gastos públicos, que perpassa as análises com foco na questão fiscal. A preocupação que os fiscalistas têm em mente é a eficiência do Estado e, nesse sentido, tem sido frequentes os debates a respeito do tamanho do Estado (participação do gasto público em relação ao PIB), principalmente desde a década de 80 , com a crise do modelo taylorista-fordista e aquilo que frequentemente tem se considerado a crise do Keynesianismo.

Na realidade, a crise do Keynesianismo é, para Navarro (1991), a constituição de um novo keynesianismo: o "keynesianismo militarista", dada a forte realocação de

\footnotetext{
${ }^{4}$ Além da função alocativa, o governo desempenha a função distributiva (associada a ajustes na distribuição de renda) e a função estabilizadora (uso da política econômica para atingir estabilidade de preços, crescimento econômico e geração de empregos em nível satisfatório) (GIAMBIAGI E ALÉM, 1999).
} 
gastos sociais para gastos militares. De acordo com Navarro (op. cit., p.204), no caso específico dos Estados Unidos, a redução de gastos na era Reagan atingiu a área social: "(...) entre 1982 e 1985, os gastos militares aumentaram em 90 bilhões de dólares, ao passo que os gastos sociais sofreram um corte de 75 bilhões de dólares". No ano 1991 os gastos militares correspondiam a $55 \%$ do orçamento federal norteamericano.

Ao mesmo tempo em que, na segunda metade dos anos 80 , vicejavam louvores às reformas da dupla Reagan-Tatcher, Villareal (1985) lançava uma incisiva crítica àquilo que ele denomina de "contra-revolução monetarista" ${ }^{5}$. Para ele, a ofensiva dos programas implantados seria parte de uma revolução dos ricos contra os pobres.

$\mathrm{O}$ ataque neoliberal contra o estado keynesiano implica, mais do que seu desaparecimento, sua 'privatização'. Pretende-se que mude suas funções, a fim de se converter num estado autoritário que reprima e controle grupos marginalizados pelo mercado ${ }^{6}$. A lei do livre mercado é a lei do mais forte (VILLAREAL, 1985, p.498).

No início dos anos 90, o Consenso de Washington daria mais consistência às reformas implantadas nos países centrais e passaria a sinalizar as "boas práticas" da administração pública pelo resto do mundo ${ }^{7}$. Nesse contexto, de redução de gastos e de manutenção do Estado mínimo, as políticas sociais passaram a ter um caráter focalizado, a fim de evitar desperdícios. Como destacam Costa e Castanhar (2003), o desafio era fazer com que o Estado funcionasse melhor com o menor custo possível.

\footnotetext{
5 Para o autor "a contra-revolução monetarista na Inglaterra desenrrola-se sob o 'thatcherismo', que consiste na aplicação do credo friedmaniano de contração monetária, eliminação do Estado como agente econômico e liberalização do mercado sob o velho dogma do 'laissez-faire, laissez-passer'. (...) Nos Estados Unidos o credo ortodoxo exerce também sua influência. Esse credo, revisado e envergando a nova roupagem da 'economia da oferta', consiste basicamente, na reabilitação da antiga Lei de Say, e configura, no contexto da reagonomia, um caso de monetarismo bastardo [em que o Estado é a causa de todos os males]". (VILLAREAL, 1985, p.45 e 47).

${ }^{6}$ Seibel (2005) mostra como a queda do welfare state provocou a emergência de um estado prisional, que tem por função precípua retirar o excedente de trabalhadores que não consegue ser absorvido pelo mercado de trabalho. Nessas circunstâncias o Estado criminaliza os excluídos e os reclui em prisões entregues à iniciativa privada.

${ }^{7}$ Ver ao respeito Tavares e Fiori (1993) e Stiglitz (2002).

Cad. de Pesq. Interdisc. em Ci-s. Hum-s., Florianópolis, v.13, n.102, p.119-134 jan/jul 2012
} 


\title{
2 Welfare State e universalização de direitos
}

$\mathrm{Na}$ visão alternativa ao Estado neoliberal, isto é, na noção do Estado de BemEstar social, ou Welfare State, cabe ao Estado papel fundamental na manutenção de condições satisfatórias de vida através de um conjunto de políticas públicas (previdência social, mercado de trabalho, saúde, educação, transporte, cuidados familiares etc.).

Mas será que é só isso? Esping-Andersen (1991, p.98) entende que a noção do Welfare State é mais ampla:

\begin{abstract}
Uma definição comum nos manuais é a de que ele envolve responsabilidade estatal no sentido de garantir o bem-estar básico dos cidadãos. Essa definição passa ao largo da questão de saber se as políticas sociais são emancipadoras ou não; se ajudam a legitimação do sistema ou não; se contradizem ou ajudam o mercado; e o que realmente significa "básico"? Não seria mais apropriado exigir de um Welfare State que satisfaça mais do que as nossas necessidades básicas ou mínimas?
\end{abstract}

Para ele, a ideia fundamental de um sistema de Welfare State é a noção de cidadania social que envolve três aspectos. O primeiro é o da garantia dos direitos sociais, isto é, a situação em que os direitos atingem o status legal de invioláveis e passam a estar associados unicamente à noção de cidadania, e não a questões de desempenho, ou à ligação com o mercado de trabalho. O segundo é que o status de cidadão passa a se sobrepor à posição social das pessoas. E, por último, destaca que o sistema não pode ser apenas considerado como um rol de direitos e garantias, mas deve levar em consideração o entrelaçamento das atividades estatais com o mercado e a família no que se refere à provisão social (ESPING-ANDERSEN, 1991).

No bojo das políticas de Welfare State, assume papel central a desmercadorização ${ }^{8}$ dos direitos sociais e a universalização de direitos. Aí cabe às instituições, com destaque para a família, papel central na elaboração das políticas públicas.

\footnotetext{
${ }^{8}$ De acordo com Esping-Andersen (1991, p.102), "a desmercadorização ocorre quando a prestação de um serviço é vista como uma questão de direito ou quando uma pessoa pode manter-se sem depender do mercado".
}

Cad. de Pesq. Interdisc. em Ci-s. Hum-s., Florianópolis, v.13, n.102, p.119-134 jan/jul 2012 
Desde o pós-guerra, nos países capitalistas centrais, a oferta universal de bens e serviços proporcionados pela efetivação das políticas públicas pareceu mesmo descartar a família, privilegiando o indivíduo cidadão. O progresso, a informação, a urbanização, o consumo fortaleceram a opção pelo indivíduo portador de direitos. Apostava-se que a família seria prescindível, substituível por um estado protetor dos direitos dos cidadãos. Nas décadas mais recentes, tanto nos países centrais quanto, sobretudo, nos países da periferia capitalista, a família volta a ser pensada como corresponsável pelo desenvolvimento dos cidadãos $^{9}$. (CARVALHO, 2006, P.267).

Portanto, a análise precisa das necessidades a serem satisfeitas via políticas públicas, bem como os agentes a serem envolvidos (governo, sociedade civil, famílias) são aspectos que devem ser levados em consideração em todas as fases de uma política pública, desde o planejamento até a avaliação.

\section{Avaliação de políticas públicas}

Há pelo menos dois conjuntos de argumentos que explicam o interesse crescente, desde os anos 80, na avaliação das políticas implementadas pelo Estado. De um lado, o que foca a sua atenção nos gastos públicos, e estabelece que na esteira do agravamento da crise fiscal se amplia a escassez de recursos para atender as demandas crescentes da população afetada pelas reformas estruturais - abertura de mercados, desestatização etc. (COSTA e CASTANHAR, 2003). O outro salienta que o interesse crescente na avaliação está ligado às mudanças que vêm ocorrendo na sociedade brasileira (ARRETCHE, 2003). E, mais especificamente, ao processo de inovação e experimentação em programas governamentais (decorrentes da Reforma do Estado, da autonomia dos governos locais e da competição eleitoral) e pelo fato de que as oportunidades abertas à participação nas políticas setoriais "[...] despertaram não apenas uma enorme curiosidade sobre os 'micro' mecanismos de funcionamento do Estado brasileiro, como também revelaram o grande desconhecimento sobre sua operação e impacto efetivo" (lb. p.7-8).

Para os primeiros, o motor da avaliação é a necessidade urgente de obter eficiência e ampliar a área de influência do governo com programas sociais e, ao

\footnotetext{
${ }^{9}$ A respeito da corresponsabilidade das famílias nos cuidados em saúde prevista na Estratégia Saúde da Família, ver Gelinski (2011).

Cad. de Pesq. Interdisc. em Ci-s. Hum-s., Florianópolis, v.13, n.102, p.119-134 jan/jul 2012
} 
mesmo tempo, dar retorno às autoridades no planejamento e na implantação de novas políticas. Para os outros, a avaliação é parte não apenas da aferição da eficiência dos gastos públicos, mas de todo um processo de conscientização da sociedade civil.

As avaliações com foco na questão fiscal têm sido denominadas gerencialistas. Em contraposição a elas, as de cunho mais acadêmico serão denominadas aqui de "não-gerencialistas". A seguir são explicitadas as metodologias ou os critérios utilizados por cada uma dessas vertentes.

\subsection{A avaliação gerencialista}

Nesta percepção, instituições multilaterais - como o Banco Mundial, o BID e a ONU - têm desempenhado papel fundamental na definição dos arcabouços metodológicos da avaliação de políticas públicas.

O BID, por exemplo, estabeleceu em 1994 o Modelo de Marco Lógico, "como modelo analítico destinado a orientar a formulação, a execução, o acompanhamento e a avaliação de programas ou de projetos governamentais" (BRASIL, 2001, p.11). O Marco Lógico é, na realidade, uma ferramenta destinada a facilitar a conceituação, o desenho, a execução e a avaliação de projetos.

Em outra iniciativa, O BID, dentro do Projeto Fortalecimento da Função Avaliativa na América do Sul, tem procurado analisar os avanços no campo da avaliação, tem promovido o intercâmbio de experiências quanto à gestão pública, principalmente entre Brasil, Argentina e Chile, e tem, também, buscado disseminar informações sobre a avaliação como parte integrante da gestão pública. No Brasil, fruto desse projeto é todo um conjunto de relatórios técnicos elaborados pelo IPEA (SILVA, 2002).

Outra instituição importante na definição de critérios de avaliação tem sido a ONU. Através de suas agências específicas, a instituição estabelece as diretrizes dos programas a serem avaliados. Costa e Castanhar (2003) destacam, nesse sentido, a metodologia recomendada pela Unicef para avaliação de programas ligados à infância. Em primeiro lugar recomendam a escolha dos critérios, sendo que os mais usados são: eficiência, eficácia, impacto ou efetividade, sustentabilidade, análise custoefetividade, satisfação do beneficiário e efetividade. Num segundo momento devem ser 
definidos os indicadores que permitam mensurar os critérios. Um outro elemento resgatado por Costa e Castanhar (op. cit.) diz respeito à delimitação dos padrões de referência para avaliar o desempenho de um programa.

Além dos elementos apontados pelo Unicef, Costa e Castanhar (op cit.) destacam que a avaliação de programas públicos (ou de ações de uma agência governamental) deve partir da definição precisa do que será avaliado. Isto é, deve estar clara a seqüência propósito > objetivo > meta > atividade. Para fins analíticos, os autores destacam as três metodológicas básicas sugeridas por Sulbrandt (1993): A avaliação de metas (realização de produção ou produtos), a avaliação de impacto (alcance do propósito ou missão) e avaliação de processos.

Sem dúvida, todo o rigor da avaliação gerencialista vai de encontro à diretriz maior de eficiência do gasto público.

\subsection{A avaliação não-gerencialista}

A discussão sobre Políticas Públicas tem sido um campo fértil dentro das ciências sociais. Ela vem ganhando espaço no contexto acadêmico, em cursos de pósgraduação e nas linhas de pesquisa de instituições de fomento.

Souza (2003) destaca o quanto a área tem crescido em qualidade e em volume, mas salienta três conjuntos de problemas, já apontados anteriormente por Melo (1999): o primeiro é o da escassa acumulação de conhecimento na área, não no sentido de acumulação linear do conhecimento mas no sentido Kuhniano do termo. O segundo no sentido inverso do primeiro - refere-se à abundância de estudos setoriais, principalmente estudos de caso, sem fortalecer os aspectos analíticos do tema nem grupos de pesquisa. O terceiro problema reside na influência dos órgãos governamentais que, pela sua proximidade, poderiam pautar as agendas de pesquisa.

Diante do interesse pelo assunto e do crescente número de trabalhos, Souza (2003) alerta para a necessidade de superar aqueles estudos que têm sido chamados de "primeira geração", com concentração na implementação das políticas públicas. Estudos esses quase sempre concentrados nos fracassos, desligados das questões políticas e com destaque para os processos racionais (desvinculados de aspectos 
políticos), presentes na implementação das políticas públicas. A autora estimula a prosseguir nos estudos da chamada "segunda geração", com ênfase no desenvolvimento de tipologias analíticas e na identificação das variáveis que causam impacto sobre os resultados das políticas públicas.

Faria (2005), por sua vez, reconhece a hegemonia que, no primeiro boom de estudos avaliativos, teve a perspectiva gerencialista estimulada por organismos multilaterais que investiram maciçamente nesses processos disponibilizando assistência técnica e financiamento. Essas avaliações (com viés top-down) eram consideradas ferramentas de planejamento destinadas aos formuladores de políticas. A ênfase estava no uso instrumental da avaliação, isto é, no fato de que os resultados da avaliação seriam utilizados para correções de rumo da política em questão ${ }^{10}$.

De acordo com Souza (2003), desde 1980, ganham relevância as análises bottom-up - ou da segunda geração - com a contribuição de Lipsky (1980). Este atentou para o fato das análises de políticas públicas estarem concentradas naqueles que decidem as políticas. Na realidade, o foco teria que estar na ação dos implementadores, na natureza do problema que se pretende resolver e nas redes que permitiram a sua adoção.

O uso de análises bottom-up justifica-se, também, pelo risco (inerente nas análises top-down) de usar instrumentos elaborados em outro contexto socioeconômico, mais especificamente nas democracias consolidadas do ocidente. Frey (2000, p.215) é categórico nisso:

\begin{abstract}
Defendo a tese de que as peculiaridades socioeconômicas e políticas das sociedades em desenvolvimento não podem ser tratadas apenas como fatores específicos de 'polity' ou 'politics', mas que é preciso uma adaptação do conjunto de instrumentos de análise de políticas públicas às condições peculiaridades das sociedades em desenvolvimento ${ }^{11}$.
\end{abstract}

\footnotetext{
${ }^{10}$ Faria (2005) distingue quatro tipos de uso da avaliação: a) a instrumental, da qual se espera decisões de mudanças ou alterações de rumo; b) a conceitual, circunscrita aos técnicos locais de um programa, que frequentemente não dispõem de muito poder de decisão; c) como instrumento de persuasão, quando se quer mobilizar apoio; e d) para "esclarecimento", quando se quer causar impacto sobre os formadores de opinião ou alterações nas crenças e na forma de ação das instituições.

${ }^{11}$ A noção de 'polity' se refere à ordem do sistema político, demarcada pelo sistema jurídico e a estrutura do sistema político administrativo. 'Politics' diz respeito aos objetivos, conteúdos e decisões de distribuição.
} 
Frey (op. cit.) alerta, também, sobre a prática, comum na 'policy analysis', de distinguir entre variáveis dependentes e independentes que com a finalidade de reduzir o nível de complexidade pode ser inadequada na análise de muitos casos empíricos (como políticas novas e conflituosas, a exemplo da política ambiental). Nem sempre se justifica a dedução meramente teórica, ou a priori, das variáveis a serem analisadas. "São indispensáveis 'representações modelares sobre possíveis concatenações explicativas' (KNOEPFEL, 1987, p.77) que podem ser obtidas por meio de estudos empíricos preliminares em cada campo de política" (FREY, 2000, p.216). Este último conclui que, em se tratando de políticas setoriais que tenham estruturas de decisão estáveis, pode ser legítimo usar o fator "instituições" como variável independente. Entretanto, se os estudos preliminares apontarem uma dinâmica expressiva das estruturas institucionais será necessário partir da pressuposição da possibilidade de dependência entre as políticas em exame e a variável institucional ${ }^{12}$.

Há todo um conjunto de elementos a serem levados em consideração em todas as fases das políticas públicas - planejamento, formulação ${ }^{13}$, execução e avaliação. Com relação a esta última, fica claro que a avaliação com foco nos custos privilegia a ação dos implementadores, mas perde riqueza ao negligenciar os atores e as redes que permitiram a implantação da política pública.

Frey (2000) destaca que a avaliação de uma política pública deve necessariamente envolver a análise da policy network, isto é, as interações das instituições e grupos, tanto do executivo, quanto do legislativo e da sociedade na concepção e na implementação de uma determinada policy. Deve, também, levar em consideração policy arena, onde os graus de conflito e consenso podem ser distinguidos pelo caráter distributivo, redistributivo, regulatório ou constitutivo das políticas. Por último, já que as redes e arenas podem mudar com o tempo, destaca a importância de ter em mente a complexidade temporal dos processos político administrativos, que podem ser observados na análise dos ciclos políticos.

\footnotetext{
${ }^{12}$ Dada a importância das instituições, os estudos sobre o desenho institucional no qual está inserida uma determinada política pública ganham relevância. Sobre aspectos conceituais, categorias de análise e vertentes teóricas do neo-institucionalismo, ver Frey (2000), Hall e Taylor (2003), March e Olsen (1984). ${ }^{13}$ Gelinski e Seibel (2008) resgatam os principais modelos de formulação de políticas públicas. Quem decide, que instituições intervêm nos processos decisórios, como se constitui uma agenda de políticas públicas e qual a finalidade das mesmas, são alguns dos aspectos abordados.
} 
Surge aí todo um espaço de discussão na avaliação de políticas públicas que parece ainda não ter um arcabouço metodológico pronto como têm as avaliações gerencialistas. Mesmo assim, o aspecto da concepção participativa vem ganhando espaço.

Fora da concepção gerencialista, as Ciências Econômicas têm avançado pouco na avaliação de políticas públicas. A "timidez" talvez esteja ligada à pouca capacidade em dialogar com outras ciências como a Sociologia ou a Ciência Política, que têm avançado na compreensão dos processos de participação popular nas políticas públicas.

\section{À guisa de conclusão... A necessidade de um novo Estado}

Ao leitor desatento de análises de políticas públicas pode parecer que a metodologia de avaliação das mesmas careça de toda uma concepção dos papéis do Estado por trás delas.

As políticas do Estado - quer sejam econômicas ou sociais - são proposições normativas, isto é, envolvem escolhas fundamentadas em juízos de valor. Os juízos de valor estarão presentes em todas as fases das políticas públicas, quer seja na concepção, na implantação ou na avaliação das mesmas.

O resgate do papel ativo do Estado na definição das políticas sociais, presente nos sistemas de Bem-Estar social, é o elemento de base daqueles que propõem avaliar as políticas públicas não apenas com foco na questão fiscal, mas incluindo os agentes envolvidos.

Mesmo que muitos autores propalem a morte do Welfare State, discutir sobre ele e sobre a importância da universalização de direitos - não atrelados a aspectos como raça, gênero, classe social ou ligações com o mercado de trabalho - pode ser o caminho para enfrentar a crescente degradação social por que passam as sociedades contemporâneas.

No Brasil, nunca chegou a se constituir um sistema de seguridade semelhante ao Welfare State de alguns países capitalistas europeus. Apesar das políticas sociais serem herdeiras dos princípios que orientaram a implantação desses sistemas, 
principalmente na Alemanha e na Inglaterra, aqui não houve propriamente a implantação de um sistema até o advento da Constituição de 1988. Só foram implantadas algumas políticas específicas de bem-estar. Políticas essas que estavam em consonância com a legitimação ideológica do sistema de exclusão muito mais do que atentos à resolução de todo um leque de problemas estruturais.

Sem desmerecer a importância das análises que apontam para a crise fiscal cabe a necessidade, destacada por Dupas (1998, p.182), de um novo Estado e de um novo acordo entre Estado e sociedade civil.

A atual carência de recursos dos governos - comprometidos a zerar seus déficits - somada à ineficiência de máquinas administrativas públicas, nos faz concluir que somente um novo e original acordo entre os governos e as sociedades civis poderá avançar. Esse novo pacto pressupõe necessariamente, a recuperação da capacidade de indução de estados nacionais éticos e fortalecidos em sua legitimidade, e a criação de estruturas eficazes que - com a íntima colaboração da sociedade civil - tenham condição de fiscalizar o cumprimento dos acordos e dos compromissos assumidos nos processos de regulação. 


\section{REFERÊNCIAS}

ARRETCHE, Marta. Dossiê agenda de pesquisa em políticas públicas. Revista Brasileira de Ciências Sociais, v.18, n.51, p.7-9, fev. 2003.

BRASIL. Tribunal de Contas da União. Técnicas de Auditoria : Marco Lógico / Tribunal de Contas da União. - Brasília : TCU, Secretaria de Fiscalização e Avaliação de Programas de Governo, 2001. Disponível em:

<http://portal2.tcu.gov.br/portal/pls/portal/docs/2054132.PDF>. Acesso em: 11 abr. 2012.

CARVALHO, Maria do Carmo Brandt de. Famílias e políticas públicas. In: ACOSTA, Ana Roja; VITALE, Maria Amália Faller (orgs.). Família: redes, laços, e políticas públicas. São Paulo: Cortez: Instituto de Estudos Especiais - PUC-SP, 2005.

COSTA, Frederico Lustosa da; CASTANHAR, José Cezar. Avaliação de programas públicos: dasafios conceituais e metodológicos. Revista de Administração Pública, v.37, n.5, p.969-992, set./out. 2003.

DUPAS, Gilberto. A lógica econômica global e a revisão do Welfare State: a urgência de um novo pacto. Estudos Avançados, USP, v.12, n.33, p.171-183, 1998.

ESPING-ANDERSEN, Gosta. As três economias polticas do welfare sate. Lua Nova, n.24, p.85-117, set. 1991.

FARIA, Carlos Aurélio Pimenta de. A política da avaliação de políticas públicas. Revista Brasileira de Ciências Sociais, v.20, n.59, p.97-109, out. 2005.

FREY, Klaus. Políticas públicas: um debate conceitual e reflexões referentes à prática da análise de políticas públicas no Brasil. Planejamento e Políticas Públicas, Brasília, n.21, p. 211-259, jun. 2000.

GIAMBIAGI, Fabio; ALÉM, Cláudia. Finanças públicas: teoria e prática no Brasil. Rio de Janeiro: Campus, 1999.

GELINSKI, Carmen Rosario Ortiz G. ; SEIBEL, Erni José. Formulação de políticas públicas: questões metodológicas relevantes. Revista de Ciências Humanas (UFSC), 
v. 42, p. 227-240, 2008. Disponível em:

$<$ http://www.cfh.ufsc.br/ revista/rch42/RCH42 artigo 10.pdf >. Acesso em 10 abr. 2012.

GELINSKI, Carmen Rosario Ortiz G. . A questão da co-responsabilidade prevista na Estratégia Saúde da Família. Politica \& Sociedade, v. 10, p. 97-114, 2011. Disponível em: <http://www.periodicos.ufsc.br/index.php/politica/article/view/2175-

7984.2011v10n19p97/19595>. Acesso em: 10 abr. 2012.

HALL, Peter A.; TAYLOS, Rosemary C.R.. As três versões do neo-institucionalismo. Lua Nova, n. 58, p.193-223, 2003.

KNOEPFEL, Peter. Probleme (International)Vergleichender politikanalysen. In: $\mathrm{KOCH}$, Rainer (org.). Verwaltungsforchung in Perspektive - Ein colloquim zur methode, zum konzept und zum transfer. Baden-Baden: Nomos, 1987. p. 56-77.

LIPSKY, Michael. Street level bureaucracy. Nova York: Russel Sage, 1980.

MARCH, J.; OLSEN, J. The New Institucionalism: organizational factors in political life. American Political Science Review, v. 78, 1984.

MELO, Marcus André. Estado, governo e políticas públicas. In: MICELI, Sérgio (org.). 0 que ler na ciência social brasileira 91970-1995). 1999. São Paulo/Brasília: Sumaré/Anpocs/Capes, p.59-100. (v.3: Ciência Política).

NAVARRO, Vicente. Welfare e "keynesianismo militarista" na era Reagan. Lua Nova, n.24, p.189-210, set. 1991.

TAVARES, Maria de Conceição; FIORI, José Luís. Desajuste global e modernização conservadora. São Paulo: Paz e Terra, 1993.

SEIBEL, Erni. O declínio do Welfare State e a emergência do estado prisional. Tempos de um novo puritanismo?. Civitas, Porto Alegre, v.5, n.1, p.93-107, jan./jun. 2005. Disponível em: <http://revistaseletronicas.pucrs.br/ojs/index.php/civitas/article/viewFile/36/1608>. Acesso em 11 abr. 2012. 
SILVA, Ricardo Toledo. Eficência e eficácia da ação governamental: uma análise comparativa e sistemas de avaliação. Brasília: IPEA, 2002. (Relatório técnico).

SOUZA, Celina. "Estado de campo" da pesquisa em políticas públicas no Brasil. Revista Brasileira de Ciências Sociais, v.18, n.51, p.15-10, fev. 2003.

STIGLITZ, Joseph E.. A globalização e seus malefícios: a promessa não cumprida de benefícios globais. São Paulo: Futura, 2002.

SULBRANDT, José. La evaluación de los programas sociales: uma perspectiva crítica de los modelos usuales. Centro Latinoemaricano de Adminisración pera el Desarrollo, 1993.

VILLAREAL, René. A contra-revolução monetarista: teoria, política econômica e ideologia do neoliberalismo. Rio de Janeiro: Record, 1985.

Artigo:

Recebido em: 11/04/2012

Aceito em: 20/07/2012 